ISSN: 1410-8917

Jurnal Kimia Sains \& Aplikasi

e-ISSN: 2597-9914

\section{Jurnal Kimia Sains dan Aplikasi Journal of Scientific and Applied Chemistry}

Journal homepage: http://ejournal.undip.ac.id/index.php/ksa

\title{
Encapsulation of Cinnamaldehyde using Chitosan: Stability, Mucoadhesive and Cinnamaldehyde Release
}

\author{
Purbowatiningrum Ria Sarjono ${ }^{a,{ }^{*},}$ Ngadiwiyana $^{a}$, Enny Fachriyah ${ }^{\mathrm{a}}$, Ismiyarto, Nor Basid \\ Adiwibawa Prasetya ${ }^{a}$, Khikmah $^{\text {a }}$ \\ ${ }^{a}$ Chemistry Department, Faculty of Sciences and Mathematics, Diponegoro University, Jalan Prof. Soedarto, Tembalang, Semarang \\ * Corresponding author: purbowatining@live.undip.ac.id
}

https://doi.org/10.14710/jksa.21.4.175-181

\section{Article Info}

Article history:

Received: 7 July 2018

Revised: 24 October 2018

Accepted: 24 October 2018

Online: 31 October 2018

Keywords:

Encapsulation,

cinnamaldehyde,

chitosan, mucoadhesive

\begin{abstract}
Cinnamaldehyde contained in cinnamon oil is useful as an antidiabetic; however, it has very low oral bioavailability. One effort to increase oral bioavailability of cinnamaldehyde is by encapsulation using chitosan. Encapsulation of cinnamaldehyde in chitosan has been successfully made in the form of powder. The aim of this study was to obtain data of stability, mucoadhesive and cinnamaldehyde release from cinnamaldehyde encapsulated chitosan. Stability tests were performed physically and chemically. Mucoadhesive tests were carried out in vitro in two steps, which were granule fabrication and then mucoadhesive test. The results showed that the levels of cinnamaldehyde decreased within 4 weeks, from the first to the fourth week $100 \%$; $99.87 \% ; 98.85 \% ; 97.33 \%$, respectively. Cinnamaldehyde powder did not change significantly in specific gravity, $\mathrm{pH}$, centrifugation and organoleptic after a month. The release precentage of cinnamaldehyde in acidic media $\mathrm{pH} 1.2$ for 180 minutes was $83.4 \%$, whereas in alkaline media $\mathrm{pH} 7.4$ for 360 minutes was $61 \%$. The cinnamaldehyde encapsulated chitosan nanoparticle powder performed mucoadhesive capacity in the gastric mucosa and in the intestinal mucosa of $91.5 \%$ and $84.61 \%$, respectively.
\end{abstract}

\section{Introduction}

Diabetes mellitus (DM) is a chronic disease characterized by a deficiency of insulin production and causes prolonged hyperglycemia with disruption in most metabolic processes in the human body [1]. In 2013, Basic Health Research (Riset Kesehatan Dasar, Riskesdas) reported that the number of people at the age over 15 years suffering DM in Indonesia was $6.9 \%$. This result has nearly doubled compared to diabetes mellitus patients in 2007. The World Health Organization (WHO) also reported that in $2014,8.5 \%$ of adults 18 years and over had diabetes and in 2015, diabetes was the direct cause of 1.6 million deaths [2]].

Ngadiwiyana et.al. [3] reported that cinnamaldehyde contained in cinnamon oil is useful as an inhibitor $\alpha$ glucosidase; however, it has very low oral bioavailability. Yuan et.al. [4] reported that the oral bioavailability of cinnamaldehyde was less than $20 \%$ at doses of 250 and $500 \mathrm{mg} / \mathrm{kg}$. Formulation development in an effort to increase oral bioavailability of cinnamaldehyde were reported by encapsulation using chitosan.

Research conducted by Fernandes et.al. [5] and Chuah et.al. [6] showed that chitosan has mucoadhesive properties. The properties can extend the residence time and contact time of the drug at the site of the application or its absorption so as to enhance the bioavailability of the drug. It may increase the therapeutic effect of drugs that are sometimes limited by shorter residence times in the gastrointestinal tract [7]. In addition to having mucoadhesive properties, chitosan can be formulated as a matrix that releases bioactive compounds in a controlled manner so that the release of bioactive compound can be controlled on the diseased organ [ $\underline{8}$ ]. 
The encapsulation of cinnamaldehyde using chitosan was successfully made by Ariestiani [9] in powder form with an encapsulation efficiency value of $74.39 \%$ and IC $_{50}$ value in inhibiting $\alpha$-glucosidase enzyme of $134.13 \mathrm{ppm}$. The result of this encapsulation can be used as pharmaceutical preparations that can improve bioavailability and control the release of cinnamaldehyde in the digestive system so that it can be utilized more effectively as antidiabetic. Stability testing of drugs is necessary so that the benefits of the drug are not lost. Moreover, the testing of drug stability is essential for product quality. Pharmaceutical stability tests will show changes in the quality of drug products related to time under the influence of environmental factors, such as temperature, humidity and light. Stability testing is generally recommended during the development of new drug products [10]. By far there have been no studies reporting the stability, mucoadhesive properties and controlled release of chitosan nanoparticles coating cinnamaldehyde. Therefore, stability, mucoadhesive and release of cinnamaldehyde in chitosan nanoparticles were carried out in this study.

\section{Experimental}

\subsection{Materials and equipments}

The materials used in this study were the cinnamaldehyde encapsulated chitosan powder obtained as reported by Ariestiani et.al. [11]; empty capsules; ethanol (pa, Merck); aquadest; $\mathrm{NaCl}$ (Merck); 37\% $\mathrm{HCl}$ (Lab Guard); Phosphate Buffered Saline (Biogear) as alkaline medium of $\mathrm{pH}=7.4$; lactose monohydrate (Merck); stomach and intestine isolated from 3 month old wistar mice (Test Animal Laboratory of Medical Faculty of Diponegoro University).

The equipments used in this research were Climatic Chamber (ICO 50 Memmert), Incubator Memmert IN-30, UV-Vis Spectrophotometer (PG Instruments Limited Model T6oU), Analytical (Ohaus), Centrifuge: PLC Series, Orbital Shaker (Tungtec Instruments CO., LTD), pH meters (LaMotte), standard glassware, mortar and pestle.

\subsection{Stability Test of Cinnamaldehyde encapsulated Nanoparticle Chitosan Powder}

Each $5 \mathrm{mg}$ of encapsulated powder was packed into an empty capsule. Packaged encapsulated powder were put into a $100 \mathrm{~mL}$ brown bottle. Stability test of encapsulated powder were carried out chemically and physically. Chemical stability tests included measuring cinnamaldehyde content in encapsulated, specific gravity and $\mathrm{pH}$. Physical stability test included centrifugation test and physical test (color, shape and smell). All encapsulated powder preparations were stored in the climatic chamber for 4 weeks with a temperature of $30^{\circ} \mathrm{C}$ and humidity of $75 \%$, except for color, shape and odor which were stored at $4^{\circ} \mathrm{C}$ and $60^{\circ} \mathrm{C}$. The temperature of sample at $4^{\circ} \mathrm{C}$ was carried out in freezer while the temperature of $60^{\circ} \mathrm{C}$ was in an incubator [르] .

\subsection{Chemical stability tests}

\subsubsection{Standard curve of cinnamaldehyde}

The standard curve was made by measuring the absorbance of cinnamaldehyde solution in distilled water with a concentration of 4, 5, 6, 7, 8 ppm at a wavelength of $292 \mathrm{~nm}$.

\subsubsection{Percentage (\%) of cinnamaldehyde contained in encapsulation (Load)}

Encapsulated powder (1 mg) was dissolved in $10 \mathrm{~mL}$ of distilled water. The absorbance was measured using UV-Vis spectrophotometer at a wavelength of $292 \mathrm{~nm}$. The absorbance was plotted into the standard curve equation, then the percentage of cinnamaldehyde contained in encapsulation was calculated using the formula (1)[13].

$\% E r=\frac{M i}{M t} \times 100 \%$

Where: Er is the total cinnamaldehyde contained in encapsulation (load); $\mathrm{Mi}$ is mass of cinnamaldehyde in encapsulation obtained from absorbance measurements $(\mathrm{mg} / 10 \mathrm{~mL})$; and $\mathrm{Mt}$ is mass of encapsulation $(\mathrm{mg} / 10 \mathrm{~mL})$

\subsubsection{Measurement of cinnamaldehyde content}

Encapsulated powder (1 mg) was dissolved in $10 \mathrm{~mL}$ of distilled water then the absorbance was measured using a UV-Vis spectrophotometer at a wavelength of 292 $\mathrm{nm}$. The measurements were taken every week for 4 weeks. The absorbance obtained was plotted into the standard curve equation. The cinnamaldehyde content was calculated using the formula (2):

Cinnamaldehyde content $=\frac{M i}{M r}$

Where: $\mathrm{Mi}$ is mass of cinnamaldehyde in encapsulation obtained from absorbance measurements (mg/10 $\mathrm{mL})$; and $\mathrm{Mr}$ is the total cinnamaldehyde contained in encapsulation.

\subsubsection{Specific gravity}

Specific gravity were measured using a picnometer. Picnometer was weighed $(A)$ then filled with encapsulated powder and weighed $\left(\mathrm{A}_{1}\right)$. Afterwards, the pycnometer was cleaned, and then filled with distilled water and weighed $\left(\mathrm{A}_{2}\right)$. Specific gravity measurement was carried out every week in 4 weeks. Specific gravity was calculated using the formula (3):

Specific gravity $=\frac{A_{1}-A}{A_{2}-A} \times 1$

\subsection{5. $\mathrm{pH}$}

A total of $5 \mathrm{mg}$ of encapsulated powder was dissolved in $20 \mathrm{~mL}$ of distilled water then measured using a $\mathrm{pH}$ meter. $\mathrm{pH}$ measurements were carried out every week in 4 weeks. 


\subsection{Physical stability tests}

\subsubsection{Centrifugation test}

A total of $5 \mathrm{mg}$ of encapsulated powder was dissolved in $5 \mathrm{~mL}$ of distilled water then centrifuged at $3000 \mathrm{rpm}$ for 10 minutes and observed. Centrifugation test were carried out every week in 4 weeks.

\subsubsection{Colour, shape and odor test}

Every week for 4 weeks, the cinnamaldehyde encapsulated powder in chitosan nanoparticles was observed its color, shape and odor at $4^{\circ} \mathrm{C}, 30^{\circ} \mathrm{C}$ and $60^{\circ} \mathrm{C}$.

\subsubsection{In vitro test of cinnamaldehyde release in acidic medium at $\mathrm{pH} 1.2$}

The cinnamaldehyde release test from chitosan nanoparticles was carried out by inserting $1 \mathrm{mg}$ of encapsulated powder into an erlenmeyer containing 10 $\mathrm{mL}$ of acidic media $\mathrm{pH}$ 1.2. The mixture was keep into the orbital shaker with a temperature of $37^{\circ} \mathrm{C}$ and a rotational speed of 100 rpm for 3 hours [14]. For every 20 minutes, absorbance were measured by taking $4 \mathrm{~mL}$ of the solution at a wavelength of $292 \mathrm{~nm}$.

\subsubsection{In alkaline medium at $\mathrm{pH} 7.4$}

The cinnamaldehyde release test from chitosan nanoparticles was carried out by inserting $5 \mathrm{mg}$ of encapsulated powder into an erlenmeyer containing 50 $\mathrm{mL}$ of phosphate buffer $\mathrm{pH}$ 7.4. The mixture was keep into the orbital shaker with a temperature of $37^{\circ} \mathrm{C}$ and a rotational speed of $100 \mathrm{rpm}$ for 6 hours [14]. For every 20 minutes, absorbance were measured by taking $4 \mathrm{~mL}$ of the solution at a wavelength of $292 \mathrm{~nm}$.

The cinnamaldehyde release in both media were calculated using formula (4):

Percent release $=\frac{M s}{M t i} \times 100 \%$

Where: Ms is cinnamaldehyde mass released into the media; Mti is total mass of cinnamaldehyde in encapsulated powder.

\subsection{In vitro mucoadhesive test}

Mucoadhesive tests were carried out by in vitro in two stages, which were granule fabrication and then mucoadhesive test [15].

\subsubsection{Granule fabrication}

Granules fabrication was carried out by grinding the mucoadhesive granule formula until homogeneous. Ethanol was then added until it formed a mass that can be clenched and then dried in an oven at $100^{\circ} \mathrm{C}$ for 10 minutes.
Tabel 1. Granule formulae (F) for mucoadhesive test

\begin{tabular}{cccc}
\hline \multirow{2}{*}{ Materials } & \multicolumn{3}{c}{ Formulae $(\mathrm{g})$} \\
\cline { 2 - 4 } & F1 & F2 & F3 \\
\hline Encapsulated powder & - & 0.5 & - \\
Chitosan & 0.5 & - & - \\
Cinnamaldehyde & - & - & 0.5 \\
*PVP K30 & 1.0 & 1.0 & 1.0 \\
Lactose & 1.0 & 1.0 & 1.0 \\
\hline
\end{tabular}

*Polyvinylpyrrolidone

\subsubsection{Mucoadhesive test}

The mucoadhesive test were carried out in the gastric and intestinal mucosa isolated from male white rats aged 3 month old. The gastric was opened, washed with $\mathrm{NaCl}$ solution, then 10 granules were weighed and placed on the surface of the gastric and intestine for 5 minutes and tilted at an angle of $45^{\circ}$. The gastric was eluted with an acidic media solution of $\mathrm{pH} 1.2$ while the intestine was eluted with a base media solution $\mathrm{pH} 7.4$ for 10 minutes. Embedded granules were calculated using the formula (5):

Percent $=\frac{G i}{G t}$

Where: $\mathrm{G}$ is percentage of granules embedded into the gastric and intestine; $\mathrm{Gi}$ is mass of embedded granule after 10 minutes; and Gt is total mass of granules.

\section{Results and discussion}

\subsection{Stability test}

\subsubsection{Chemical stability}

Chemical stability was investigated through testing cinnamaldehyde content, specific gravity and $\mathrm{pH}$ changes.

\subsubsection{Cinnamaldehyde content}

Measurement of the cinnamaldehyde content in the encapsulated powder were carried out every week to determine its stability. The results are shown in Figure 1.

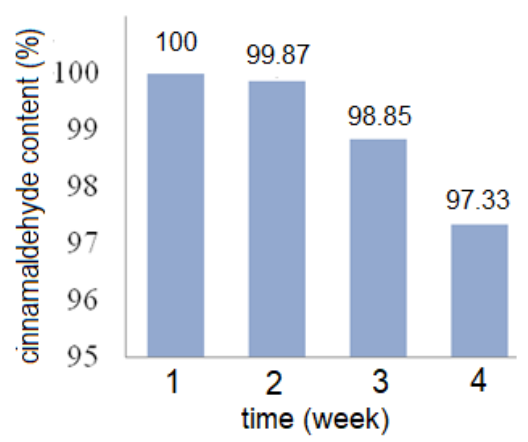

Figure 1. Cinnamaldehyde content per week

The cinnamaldehyde content in the first week was $100 \%$. This shows that cinnamaldehyde in the encapsulation is stabile in a week. Cinnamaldehyde levels 
begin to reduce in the second to fourth week. After four weeks, the cinnamaldehyde content has decreased by $2.67 \%$, which is probably influenced by temperature and humidity causing the crosslinks between chitosan and tripolyphosphate begin to break and the chains between polymer chitosan reattach each other (aggregation occurs) so that the encapsulated cinnamaldehyde starts to release. Since the level of cinnamaldehyde after 4 weeks remains high at $97.33 \%$ with a half-life of 72 weeks, it can be concluded that the encapsulated powder is quite stable during storage under certain conditions.

\subsubsection{Specific gravity}

Specific gravity is the ratio of the weight of a substance to the weight of a standard substance at the same volume and temperature. Specific gravity describes the relationship between the weight of a substance to the weight of a standard substance [16]. Table 2 shows the specific gravity of encapsulated powder stored in the climatic chamber for 4 weeks. It can be seen that encapsulated powders did not experience specific gravity changes. In other words, the encapsulated powder remains stable even after 4 weeks of storage.

Tabel 2 Specific gravity of encapsulated powder

\begin{tabular}{cc}
\hline Week & Specific gravity $(\mathrm{g} / \mathrm{mL})$ \\
\hline 1 & 0.0059 \\
2 & 0.0048 \\
3 & 0.0045 \\
4 & 0.0047 \\
\hline Mean & 0.0050 \\
\hline
\end{tabular}

\subsection{4. $\mathrm{pH}$}

$\mathrm{pH}$ measurement aims to determine the $\mathrm{pH}$ value of the encapsulated powder preparation stored in the climatic chamber for 4 weeks. $\mathrm{pH}$ is one of the parameters to test stability of the drug in a formulation. The $\mathrm{pH}$ value of the encapsulated powder from the first week to the fourth week is shown in Table 3. Table 3 shows the $\mathrm{pH}$ value of encapsulated powder after 4 weeks remains stable at 6.7. This $\mathrm{pH}$ value of 6.7 shows that the encapsulated powder is acidic. The nature of this acid is influenced from hydrogen alpha position on carbonyl groups in cinnamaldehyde.

Tabel $3 \mathrm{pH}$ of encapsulated powder

\begin{tabular}{cc}
\hline Week & $\mathrm{pH}$ \\
\hline 1 & 6.71 \\
2 & 6.67 \\
3 & 6.65 \\
4 & 6.72 \\
Mean & 6.7 \\
\hline
\end{tabular}

\subsection{Physical stability}

\subsubsection{Centrifugation}

In this test, encapsulated powder formulation were centrifuged at $3000 \mathrm{rpm}$ for 10 minutes. This centrifugation test used to accelerate centrifugal force to separate two or more substances that have a different density, such as between liquids or between liquids with a solid [17]. The results show no changes, in which two phases still remains (liquid phase of distilled water and solid phase of encapsulated powder) to show that before and after centrifuging the encapsulated powder does not mix with distilled water. This shows that cinnamaldehyde is still encapsulated in chitosan nanoparticles.

\subsubsection{Colour, shape and odor tests}

Color, shape and odor tests were carried out to determine the characteristics of encapsulated powder preparations and as a simple initial introduction by using five human senses. The test results show that all formulas have similarities in terms of shape and smell. After 4 weeks the formulations remain in powder form and the smell is still typical of cinnamaldehyde. Encapsulated powder preparations have different colors at each tested temperature, but no changes occur every week. The formulations at the temperature of 4,30 and $60^{\circ} \mathrm{C}$ show yellow, orange and solid orange colour, respectively.

\subsubsection{In vitro test of cinnamaldehyde release}

The release of cinnamaldehyde in chitosan nanoparticles was carried out on an acid medium with $\mathrm{pH}$ 1.2 to simulate the $\mathrm{pH}$ of gastric while medium alkaline fluids with $\mathrm{pH} 7.4$ to simulate the $\mathrm{pH}$ of intestinal fluid. The release test was carried out using an orbital shaker at $37^{\circ} \mathrm{C}$ with a stirring speed of $100 \mathrm{rpm} .37^{\circ} \mathrm{C}$ temperature was used to resemble human body temperature and stirring aimed to describe bowel movements. The time used in the release test was adjusted to the digestion time in the human body, which was about 1-3 hours in acidic medium and $4 \pm 1.5$ hours in alkaline medium [14] Measurement of percentage release using standard cinnamaldehyde graphs on acid and base medium.

Cinnamaldehyde nanoencapsulation aims to hold the rate of drug release in the stomach. The profile of drug or active substance release is determined by the cross-link density of the microspheres, the size, and the initial content of the drug [18]. Increasing cross-link inhibits swelling of beads in the medium and diffusion of the drug which results in a lower release rate. Smaller beads have a wider contact area with media so that they support faster drug release compared to larger beads[18]. The mechanism of drug or active substance release begins with the swelling process when the beads come into contact with the dissolution medium followed by liquid penetration into the matrix [19] resulting in a tenuous polymer structure [20]. 


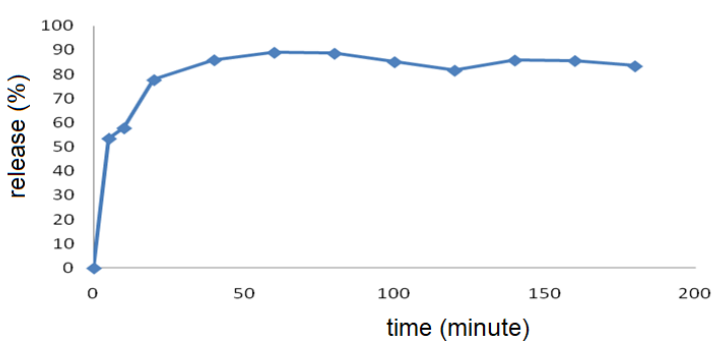

Figure 2. Cinnamaldehyde release in acidic medium at pH 1.2

The release of cinnamaldehyde on acidic medium at $\mathrm{pH} 1.2$ within 5 minutes was $53.5 \%$ (Fig 2). It shows that quite large number of cinnamaldehyde has been released in the media which means that the encapsulation has begun to break down. The presence of cinnamaldehyde in the media is caused by protonation of $-\mathrm{NH}_{2}$ group of chitosan which is not crosslinked with TPP [21]. Swelling then occurs in which the liquid enter the polymer matrix causing cinnamaldehyde to diffuse into the external environment.

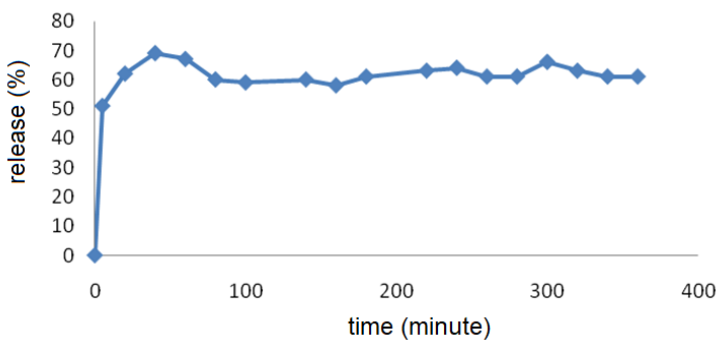

Figure 3. Cinnamaldehyde release in alkaline medium at $\mathrm{pH} 7.4$

Figure 3 shows the release of cinnamaldehyde after 5 minutes was $51 \%$. This result is greater than the release in acidic media in the same minute, which is caused by deprotonation in alkaline media. Lin et.al.[22] stated that chitosan-TPP particles become unstable and begin to break at $\mathrm{pH}>7.2$ due to deprotonation of the amino group of chitosan.

Figure 3 shows that with the increasing incubation time the release of cinnamaldehyde is increase, which is $61 \%$ in the 360 th minute. This shows that the crosslink between chitosan and tripolyphosphate is broken resulted in the releasing of cinnamaldehyde [6].

\subsection{Mucoadhesive test}

This mucoadhesive test aims to look at the adhesion strength of granule formulas in the rat stomach and intestinal mucosa. The mucoadhesive system can be used to target drugs to certain parts of the body for long periods of time to improve the bioavailability of the drug [23]. Bioadhesive is the attachment of either synthesis or non-synthesis material in biological tissue for a long period of time. The term mucoadhesion refers to the case of bioadhesion where the mucosa is the biological tissue as the site attachment [24].
Granule formulation (F) consists of F1 (chitosan), F2 (encapsulated powder) and F3 (cinnamaldehyde). The mucoadhesive test was carried out by spreading the granule formulation on the mucosa of the rat and left it in contact between the granule and the mucosafor 5 minutes. It was then eluted with acidic medium of $\mathrm{pH} 1.2$ and alkaline medium of $\mathrm{pH} 7.4$ for 10 minutes. The results of mucoadhesive tests on rat stomach and intestine are shown in Figure 5.

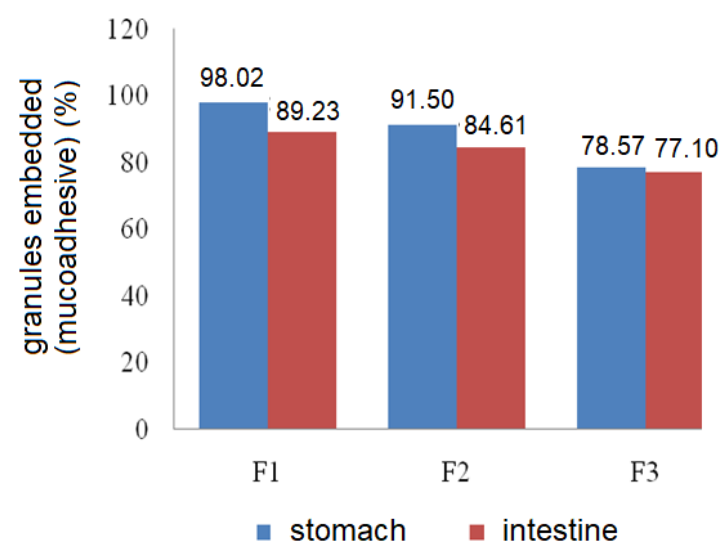

Figure 4. Mucoadhesive test on stomach and intestine of white rats

Figure 4 shows that all formulas have high mucoadhesive strength. This is due to the adhesion process that occurs in each formula with mucin in the rat stomach and intestinal mucous membranes.

Figure 4 shows that the mucoadhesive strength of all formulas in the gastric mucosa are higher than in the intestinal mucosa. This is because protonation occurs in the stomach so that many positive charges are formed. The more positive charges, the more ionic bonds are formed by the negative charge of mucin $[\underline{25}, \underline{26}]$. F3 data showed that without using chitosan, granules attached to the stomach or intestine were less compared to F1 and F2 using chitosan polymer. In F3, it does not form electrostatic interactions with mucin. Cinnamaldehyde is possible to perform hydrogen binding with gastric or intestinal mucin, whereas in F1 and F2 it can interact electrostatically between chitosan and mucin. Figure 5 shows the approach to hydrogen bonding that might occur between cinnamaldehyde and gastric or intestinal mucin. 
<smiles>N[C@@H](CCC(=O)O)C(=O)OC=CC=Cc1ccccc1</smiles>

Cinnamaldehyde

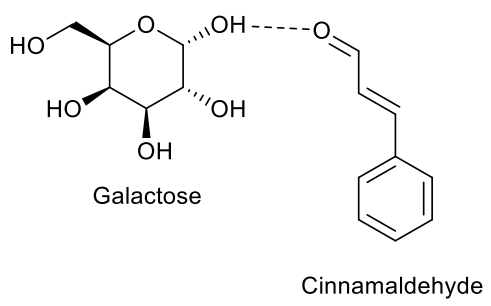

Figure 5. Hydrogen bonding between cinnamaldehyde with glutamic acid and galactose

In F1 which is a chitosan polymer, the percentage of granules attached to the stomach is $98.02 \%$ and in the intestine is $89.23 \%$, while F2 which is chitosancinnamaldehyde nanoparticles has a smaller percentage in stomach of $91.5 \%$ and in the intestine of $84.61 \%$. The both formulas contain chitosan polymers, but F2 contain chitosan in nanoparticle form and is crosslinked with tripolyphosphate so that the amines are relatively few to interact with mucin. In addition, a tight matrix cause steric resistance to interact with mucin. As a result, the tendency of chitosan nanoparticles to mucoadhesive is reduced []].

\section{Conclusion}

It can be concluded that the cinnamaldehyde content is quite stable and its specific gravity, $\mathrm{pH}$, centrifugation and organoleptic of cinnamaldehyde powder do not experience significant changes. The chitosancinnamaldehyde nanoparticles encapsulated powder has mucoadhesive capacity of $91.5 \%$ in the gastric mucosa and $84.61 \%$ in the intestinal mucosa. The release of cinnamaldehyde in acidic media $\mathrm{pH} 1.2$ for 180 minutes was $83.4 \%$, whereas in alkaline media $\mathrm{pH} 7.4$ for 360 minutes was $61 \%$. The encapsulated powders show better mucoadhesive properties than cinnamaldehyde and the presence of chitosan nanoparticles can improve the bioavailability of cinnamaldehyde.

\section{References}

[1] Salim Bastaki, Review Diabetes mellitus and its treatment, International Journal of Diabetes and Metabolism, 13, (2005) 111-134

[2] WHO, Global report on diabetes, in, World Health Organisation, 2016.

[3] Ngadiwiyana, Ismiyarto, Nor Basid Adiwibawa Prasetya and Purbowatiningrum Ria Sarjono, Potensi sinamaldehid hasil isolasi minyak kayu manis sebagai senyawa antidiabetes, Majalah Farmasi Indonesia, 22, 1, (2011) 9-14

[4] J. H. Yuan, M. P. Dieter, J. R. Bucher and C. W. Jameson, Toxicokinetics of cinnamaldehyde in F344 rats, Food and Chemical Toxicology, 30, 12, (1992) 997-1004 https://doi.org/10.1016/0278-6915(92)90109-X

[5] Mariana Fernandes, Inês C. Gonçalves, Stefania Nardecchia, Isabel F. Amaral, Mário A. Barbosa and M. Cristina L. Martins, Modulation of stability and mucoadhesive properties of chitosan microspheres for therapeutic gastric application, International Journal of Pharmaceutics, 454, 1, (2013) 116-124 https://doi.org/10.1016/j.ijpharm.2013.06.068

[6] Lay Hong Chuah, Nashiru Billa, Clive J. Roberts, Jonathan C. Burley and Sivakumar Manickam, Curcumin-Containing Chitosan Nanoparticles As A Potential Mucoadhesive Delivery System To The Colon, Pharmaceutical development and technology, 18, 3, (2013) 591-599 https://doi.org/10.3109/10837450.2011.640688

[7] K. P. R. Chowdary and Y. Srinivasa Rao, Design and In Vitro and In Vivo Evaluation of Mucoadhesive Microcapsules of Glipizide For Oral Controlled Release: A Technical Note, AAPS PharmSciTech, 4, 3, (2003) https://dx.doi.org/10.1208\%2Fpt040339

87-92

[8] M. Prabaharan, Review Paper: Chitosan Derivatives as Promosing Materials for Controlled Drug Delivery, J Biomater Appl, 23, (2008) 5-36

[9] Bonita Ariestiani, Enkapsulasi Sinamaldehid dalam Nanopartikel Kitosan sebagai inhibitor $\alpha-$ glukosidase. Skripsi, Universitas Diponegoro, Semarang

[10] Madaswamy S. Muthu and Si Shen Feng, Pharmeceutical Stability Aspects of Nanomedicines, Future Medicine, 4, 8, (2009) 857-860 https://doi.org/10.2217/nnm.09.75

[11] Bonita Ariestiani, Purbowatingrum Ria Sarjono, Ngadiwiyana, Ismiyarto, Enny Fachriyah and Khikmah Nurani, Antioxidant activity from encapsulated Cinnamaldehyde-Chitosan, Journal of Physics: Conference Series, 1025, (2018) 012132 http://dx.doi.org/10.1088/1742-6596/1025/1/012132

[12] Mahdi Jufri, Effionora Anwar and Putri Utami, Uji Stabilitas Sediaan Mikroemulsi Menggunakan Hidrolisat Pati (De 35-40) Sebagai Stabilizer, Majalah Ilmu Kefarmasian, 3, 1, (2006) 8-21 http://dx.doi.org/10.7454/psr.v3i1.3396

[13] Yaoqi Tian, Yanqiao Zhu, Mohanad Bashari, Xiuting $\mathrm{Hu}$, Xueming $\mathrm{Xu}$ and Zhengyu Jin, Identification and releasing characteristics of high-amylose corn starch-cinnamaldehyde inclusion complex prepared using ultrasound treatment, Carbohydrate Polymers, 91, 2, (2013) 586-589 https://doi.org/10.1016/j.carbpol.2012.09.008

[14] G.S. Kwon, Polymeric Drug Delivery Systems, Taylor \& Francis, 2005.

[15] Salman Umar, Wida Ningsih and Monalisa Meliana, Formulasi Granul Mukoadhesif Ketoprofen 
Menggunakan Polimer Kitosan, Jurnal Sains Farmasi \& Klinis, 1, 1, (2014) 48-53

[16] Howard Ansel, C.. and Shelly J. Prince, Pharmaceutical Calculations The Pharmacist's Handbook, Lippincott Williams \& Wilkins, USA, 2004.

[17] Walaa El-Sayed and Tahany G. M. Mohammad, Preparation and Characterization of Alternative OilIn-Water Emulsion Formulation of Deltamethrin, American Journal of Experimental Agriculture, 4, 4, (2014) https://doi.org/10.9734/AJEA/2014/6372

[18] B. Chithambara Thanoo, M. C. Sunny and A. Jayakrishnan, Cross-linked Chitosan Microspheres: Preparation and Evaluation as a Matrix for the Controlled Release of Pharmaceuticals, Journal of Pharmacy and Pharmacology, 44, 4, (1992) 283-286 http://dx.doi.org/10.1111/j.20427158.1992.tb03607.x

[19] F Nata, P. Sugita and A. Syahriza, Diffusion Behavior Of Ketoprofen Through Chitosan-Gum Guar Membrans, Prosiding Internationl Conference and Workshop on Basic and Applied Science 2007, SurabayaIndonesia, (2007)

[20]So Yeon Kim, Sung Min Cho, Young Moo Lee and Seon Jeong Kim, Thermo- and pH-responsive behaviors of graft copolymer and blend based on chitosan and Nisopropylacrylamide, Journal of Applied Polymer Science, 78, 7, (2000) 1381-1391 https://doi.org/10.1002/10974628(20001114)78:7\%3C1381::AIDAPP90\%3E3.0.CO;2-M

[21] Nadia A. Al-Assady, Wesam A. K. Hussein and Hadi A. Jabir, Preparation, Characterization, and Diltiazem $\mathrm{HCl}$ Release Study of Chitosan / poly(vinyl alcohol) Microspheres, Iraqi National Journal of Chemistry, 41, (2011) 113-126

[22]Yu-Hsin Lin, Kiran Sonaje, Kurt M. Lin, JyuhnHuarng Juang, Fwu-Long Mi, Han-Wen Yang and Hsing-Wen Sung, Multi-ion-crosslinked nanoparticles with $\mathrm{pH}$-responsive characteristics for oral delivery of protein drugs, Journal of Controlled Release, 132, 2, (2008) 141-149 https://doi.org/10.1016/j.jconrel.2008.08.020

[23]James Swarbrick and J. C. Boylan, Encyclopedia of Pharmaceutical Technology. Vol 10., Marcel Dekker, New York, 1994.

[24]S. U. Zate, P.I. Kothawade, G.H. Mahale, K.P. Kapse and S.P. Anantwar, Gastro Retentive Bioadhesive Drug Delivery System: A Review, International Journal of PharmTech Research, 2, 2, (2010) 1227-1235

[25]Ping He, Stanley S. Davis and Lisbeth Illum, In vitro evaluation of the mucoadhesive properties of chitosan microspheres, International Journal of Pharmaceutics, 166, 1, (1998) 75-88 https://doi.org/10.1016/S0378-5173(98)00027-1

[26]Hsi-Ya Huang, Kuang-Lung Kuo and You-Zung Hsieh, Determination of cinnamaldehyde, cinnamic acid, paeoniflorin, glycyrrhizin and [6]-gingerol in the traditional Chinese medicinal preparation Kueichih-tang by cyclodextrin-modified micellar electrokinetic chromatography, Journal of Chromatography A, 771, 1, (1997) 267-274 https://doi.org/10.1016/S0021-9673(97)00136-2 